¿ DON

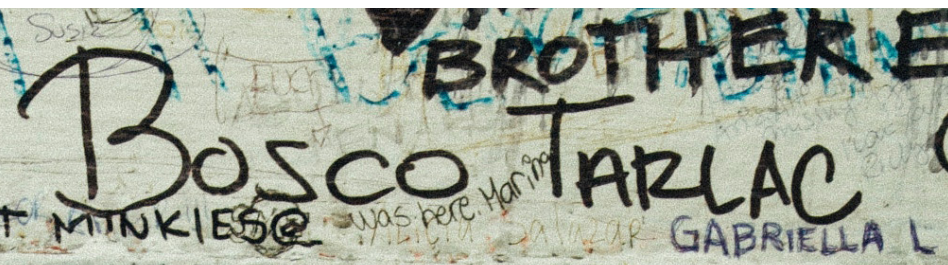

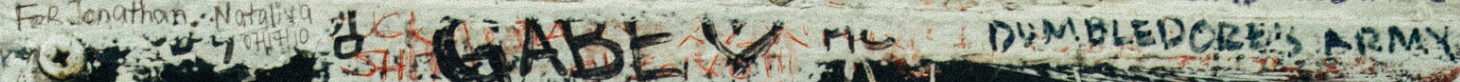

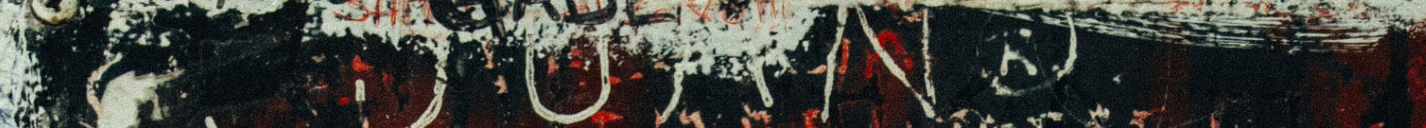

(3)

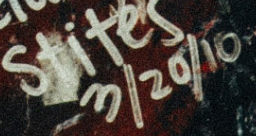

ifle

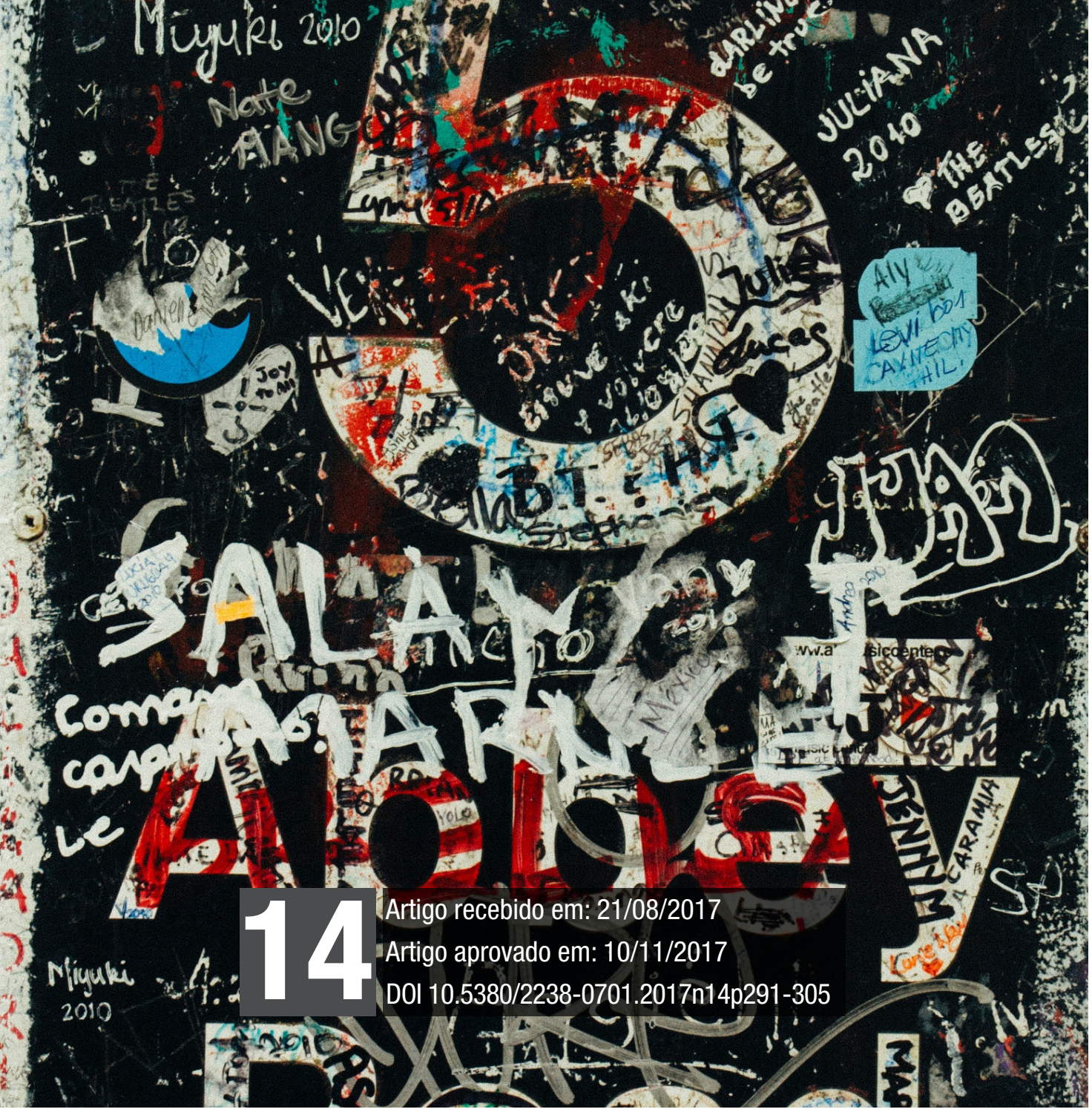


Choque. Tédio. Publicidade. 


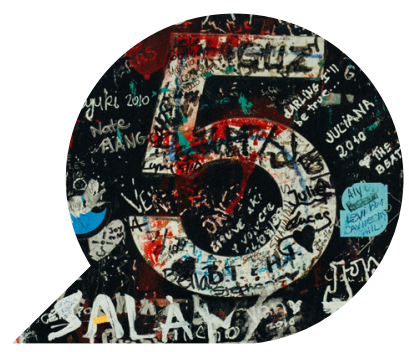

\title{
"Bem-vindo à próxima fase": a cultura do choque e o fim do tédio
}

\author{
"Welcome to the next level": \\ the culture of shock and the end of boredom \\ "Bienvenido al siguiente nivel": \\ la cultura del choque y el fin del aburrimiento
}

RODOLFO RORATO LONDERO*

Resumo: Neste ensaio, discutimos o conceito de choque, desde sua formulação como técnica comercial pela publicidade até suas consequências para o atual regime de atenção. Propomos que a intensificação do choque a partir do consumo extremo de imagens, como o percebido na cultura dos videogames, contribui para o fortalecimento de uma atenção fragmentada e inquieta. Entendemos assim que a "cultura do déficit de atenção" (Türcke) e o desenvolvimento de uma "atenção multitarefa" (Han) são as duas faces de um mesmo processo. Afirmamos também que o tédio é uma dimensão humana ameaçada pelo atual regime de atenção, pois a busca constante de elementos portadores de significado impede a contemplação do vazio, característica marcante do tédio e da própria humanidade.

Palavras-chave: Choque; Atenção; Tédio; Publicidade.

* Doutor em Estudos Literários pela Universidade Federal de Santa Maria. Professor do Departamento de Comunicação e do Programa de Pós-Graduação em Comunicação da Universidade Estadual de Londrina. E-mail: rodolfolondero@bol.com.br 


\begin{abstract}
In this essay, we discuss the concept of shock, from its formulation as a commercial technique by advertising to its consequences for the current regime of attention. We propose that the intensification of the shock by extreme consumption of images, as noted in the culture of video games, contributes to the strengthening of fragmented and restless attention. We understand that the "attention deficit culture" (Türcke) and the development of "multitasking attention" (Han) are the two faces of the same process. We also affirm that boredom is a human dimension threatened by the current regime of attention, since the constant search for meaning-bearing elements prevents contemplation of emptiness, a hallmark of boredom and humanity itself.
\end{abstract}

Keywords: Shock; Attention; Boredom; Advertising.

Resumen: En este ensayo discutimos el concepto de choque, desde su formulación como técnica comercial por la publicidad hasta sus consecuencias para el actual régimen de atención. Proponemos que la intensificación del choque a partir del consumo extremo de imágenes, como el percibido en la cultura de los videojuegos, contribuye al fortalecimiento de una atención fragmentada e inquieta. Entendemos así que la "cultura del déficit de atención" (Türcke) y el desarrollo de una "atención multitarea" (Han) son las dos caras de un mismo proceso. Afirmamos también que el aburrimiento es una dimensión humana amenazada por el actual régimen de atención, pues la búsqueda constante de elementos portadores de significado impide la contemplación del vacío, característica del aburrimiento y de la propia humanidad.

Palabras clave: Choque; Atención; Aburrimiento; Publicidad. 


\section{Ensaio}

No famoso ensaio "A obra de arte na época de suas técnicas de reprodução", na tentativa de compreender a nova percepção instaurada pelo cinema, Walter Benjamin recorre ao conceito de choque, ainda hoje utilizado entre os profissionais de mídia, mesmo que às vezes na forma abrandada de impacto - apesar de etimologias diferentes, ambas as palavras significam originalmente "bater contra" (choque) ou "empurrar contra" (impacto). Benjamin dizia que, no cinema, "a sucessão de imagens impede qualquer associação no espírito do espectador. Daí é que vem a sua influência traumatizante; como tudo que choca, o filme somente pode ser apreendido mediante um esforço maior de atenção" (BENJAMIN, 1983, p. 25). Por sua vez, em "Cansaço da informação", Byung-Chul Han argumenta que o conceito de choque de Benjamin não é o mais adequado para pensar a percepção das imagens técnicas contemporâneas. Para Han (2014a), o choque é uma forma de defesa imunológica, uma estratégia para bloquear o excesso de informação das imagens. Entretanto, como atualmente sofremos de baixa defesa imunológica, a informação circula livremente. Não há mais choque para nos defendermos.

Para melhor compreender o nascimento e a morte (?) do conceito de choque, recorreremos à publicidade, pois esse conceito a acompanha desde seus primórdios. Na verdade, podemos entender o choque publicitário como uma técnica comercial, decorrente da primazia da atenção estabelecida pelo mais antigo modelo de publicidade, o modelo AIDA (atenção-interesse-desejo-ação). No início do século XX, St. Elmo Lewis, creditado como criador do modelo, dizia que, "se nós não pudermos ganhar a atenção do leitor, é manifestamente impossível para nós interessá-lo e convencê-lo" (LEWIS, 1908, p. 95). De modo mais agressivo, George French afirmava que o olho "não está procurando pelo anúncio, mas o anúncio precisa atacar o olho, aprisioná-lo e obrigá-lo a enviar a mensagem para o cérebro" (FRENCH, 1909, p. 158). O então crescente uso de ilustrações em anúncios também contribuiu para a discussão em torno da primazia da atenção, apesar de opiniões divergentes: enquanto Claude Hopkins dizia, em Scientific Advertising, que não se deve usar ilustrações para atrair a atenção (HOPKINS, 1970), William Larned justificava o uso de ilustrações por causa deste e outros motivos, mostrando, em Illustration in Advertising, como anúncios exclusivamente ilustrados garantem o máximo de atenção do leitor (LARNED, 1925). 
Saltando algumas décadas, Abraham Moles, em uma conhecida obra sobre o cartaz publicitário, nos fala de "choque cromático", "choque semântico", "choque emocional", etc., como recursos à disposição da publicidade para chamar atenção. Moles (1974) recorre à teoria da gestalt para explicar porque o choque funciona: ele destaca a mensagem publicitária como figura, separando-a de um fundo indefinido. Como ele diz, "ao lado do cinzento e do descorado da rua, os polos de atração propostos ao transeunte são o cartaz e a vitrine" (MOLES, 1974, p. 220; grifo do autor). Entretanto, como já argumentamos em outra oportunidade (LONDERO, 2013), em um cenário de poluição informativa-visual, o excesso de publicidade se transforma no cinza da rua, no fundo absoluto para uma figura cada vez mais indefinida. Sendo assim, o abuso da técnica do choque resulta em um "efeito papel-de-parede", como reconhecem Al Ries e Laura Ries² (RIES; RIES, 2002). Desse modo, acompanhando a história do choque publicitário, podemos concordar com Han e também falar em um fim do choque, mas desta vez não como estratégia perceptiva, e sim como técnica comercial.

Vejamos agora um contraponto. Christoph Türcke, em seu ensaio "Cultura do déficit de atenção", afirma que

o choque da imagem se tornou o foco de um regime de atenção global, que embota a percepção justamente por uma contínua excitação, um contínuo despertar. Os criadores de programas televisivos não contam mais com um espectador mediano que acompanha longos programas do início ao fim. Eles calculam de antemão que ele mudará de canal à menor queda de tensão percebida, e ficam felizes quando conseguem retê-lo ao menos nos destaques do programa, que são anunciados com chamadas espetaculares. Esse espectador representa o regime de atenção do choque imagético, e dita o modelo até para o leitor de hoje, mesmo o leitor intelectual (TÜRCKE, 2015).

Ao contrário de Han, Türcke compreende o choque como parte de um regime de atenção global. Portanto, não se trata de uma estratégia de defesa do espectador, mas de uma estratégia de ataque da programação, golpeando o espectador quando há uma queda de tensão percebida. É a

\footnotetext{
${ }^{2}$ Quando propôs a conhecida técnica de posicionamento, no final dos anos 1980, Al Ries já apontava para essa saturação de publicidade, apesar de sua própria técnica exigir mais publicidade: "O ingrediente principal para se assegurar uma posição de liderança é chegar primeiro na mente do consumidor. O ingrediente principal para se manter nessa posição é reforça-la" (RIES; TROUT, 1987, p. 35). Portanto, ao invés de endossar a crítica dos Ries, não podemos esquecer que a própria publicidade fomentou esse cenário que ela atualmente critica (LONDERO, 2016).
} 
mesma argumentação de Kerckhove (1997) quando afirma que a televisão produz muitos cortes, impossibilitando qualquer reação consciente. Essas condições produzem uma cultura do déficit de atenção: "Bilhões de pequenos choques audiovisuais estimulam a atenção humana o tempo todo - e por isso a desgastam. Essa é a lei do déficit de atenção, cuja dinâmica permeia toda a nossa cultura" (TÜRCKE, 2015).

Mas se o choque é uma técnica com os dias contados, então o diagnóstico de Türcke, de uma cultura do déficit de atenção, é inválido? Provavelmente não, pois Moles e Türcke abordam mídias diferentes: cartaz e televisão. Se considerarmos o regime de atenção/distração característico da modernidade (CRARY, 2014a) e compararmos os dois tipos de mídia, perceberemos que, no caso do cartaz, o transeunte produz os cortes ao deslocar seu campo visual entre os cartazes (atenção) e demais elementos cinzentos da rua (distração); entretanto, no caso da televisão, o próprio aparelho incorpora os cortes antes produzidos pelo transeunte. É como se a televisão fosse um flâneur automatizado. Sendo assim, a crítica do "efeito papel-de-parede" é inadequada para se referir à publicidade televisiva: podemos até adquirir uma percepção seletiva resistente aos spots, mas não podemos esquecer que a programação televisiva se desenvolve como um fluxo contínuo (WILLIAMS, 2016), um fluxo que possuímos pouco controle, pois não podemos pará-lo. Como afirma Türcke, "o efeito de choque se abranda de verdade apenas quando as telas passam a ser cenário de todos os dias, mas a intermitente 'mudança de lugares e ângulos' não para de modo nenhum" (TÜRCKE, 2015). Deste modo, não faz diferença se os cortes são produzidos pela televisão ou por nós mesmos, pois ambos contribuem para o regime de atenção denunciado pelo autor, para uma atenção fragmentada ou multitarefa (ver adiante).

Apesar de Han e Türcke falarem em choque a partir de entradas diferentes, não podemos considerá-las excludentes; na verdade, devemos entendê-las como complementares. Como não temos a defesa imunológica do choque, cedo ou tarde padecemos de cansaço da informação. Enquanto antes o choque nos fazia desviar do excesso de informação, agora somos soterrados por esse excesso, levados à exaustão. Nas primeiras vezes, como resposta, iremos desligar a televisão. Nas próximas vezes, ultrapassando o limiar da exaustão, iremos mantê-la ligada, afetados pelo cansaço, mas animados pelos choques. $\mathrm{Ou}$ seja, a televisão roubou nossa principal defesa para utilizá-la contra 
nós. É somente assim que conseguimos compreender esse comportamento até então inédito na história da humanidade, como destaca Jonathan Crary: "A reorganização relativamente repentina e ubíqua do tempo e da atividade humanos que acompanhou a televisão teve poucos precedentes históricos. [...] No intervalo de menos de quinze anos, populações inteiras foram colocadas em um estado prolongado de relativa imobilidade" (CRARY, 2014b, p. 90).

Das populações imobilizadas diante da televisão, agora temos os jogadores de videogame, capazes de assimilar uma quantidade infinitamente maior de choques. Em A guerra dos consoles, Blake Harris faz um relato interessante sobre a criação da campanha que definiu o mais conhecido slogan da Sega: "Bem-vindo à próxima fase". Vale ressaltar que a campanha contou com a participação de Jon Steel, liderando uma pesquisa etnográfica sobre os valores e costumes da tribo gamer. O resultado da campanha é assim descrito por Harris:

Cortes rápidos. Zooms loucos. Ângulos de câmera ousados. Era como assistir a um comercial em que alguém tivesse apertado a tecla "avançar” do videocassete. Punk tocando no volume máximo. Luzes cintilantes. Closes agressivos. Parecia um clipe de música, mas só se o vídeo estivesse sofrendo de distúrbio bipolar e houvesse acabado de ingerir um coquetel de heroína, cocaína e anfetamina. Luzes esquisitas, atores não muito bonitos, uma narrativa não linear - a coisa toda era irritante, causava dores de cabeça e enlouquecia os sentidos; mas era incrível. E, para concluir, no fim de cada comercial um maculo gritava: "Sega!" (HARRIS, 2015, p. 319-320).

Não podemos menosprezar a importância dos videogames para a formação daquilo que Han (2015) chama de sociedade do desempenho. "Bem-vindo à próxima fase": para alcançar a próxima fase, tudo depende de você. Não podemos falar em sociedade disciplinar, pois não há punição por parte do videogame para quem continua sempre na mesma fase. São os próprios jogadores quem dizem "eu posso", pois eles sabem que, se persistirem, podem alcançar a próxima fase. O videogame é a realização da sociedade do desempenho: autocobrança e satisfação.

Podemos concluir, a partir da campanha, que a próxima fase (da sociedade, da humanidade?) exigirá que acompanhemos imagens velozes, vertiginosas, carregadas de nonsense. E para isso precisaremos estar dopados, acelerados química e psiquicamente. Ao pesquisar a tribo ga- 
mer no início dos anos 1990, talvez Steel não tenha percebido que aqueles adolescentes não eram apenas um público-alvo, mas uma nova raça pós-humana. Eles seriam capazes de proezas maiores, como achatarem sua visão para acomodar telas móveis e se inquietarem antes dos dez segundos de um snap.

Fazemos referência ao darwinismo tecnológico, oriundo do pós -humanismo pois podemos acreditar que nosso atual regime de atenção é uma evolução. Ao falar da "mutação evolutiva" de David Bowie em The man who fell to earth, Fredric Jameson afirma que "o espectador pós-moderno, no entanto, é chamado a fazer o impossível, ou seja, ver todas as telas ao mesmo tempo" (JAMESON, 2006, p. 57). Entretanto, essa mutação não é evolutiva, mas involutiva:

A técnica temporal e de atenção multitasking (multitarefa) não representa nenhum progresso civilizatório. A multitarefa não é uma capacidade para a qual só seria capaz o homem na sociedade trabalhista e de informação pós-moderna. Trata-se antes de um retrocesso. A multitarefa está amplamente disseminada entre os animais em estado selvagem. Trata-se de uma técnica de atenção, indispensável para sobreviver na vida selvagem. Um animal ocupado no exercício da mastigação de sua comida tem de ocupar-se ao mesmo tempo também com outras atividades. Deve cuidar para que, ao comer, ele próprio não acabe comido. Ao mesmo tempo tem de vigiar sua prole e manter o olho em seu (sua) parceiro(a). Na vida selvagem, o animal está obrigado a dividir sua atenção em diversas atividades. Por isso, não é capaz de aprofundamento contemplativo - nem no comer nem no copular. $\mathrm{O}$ animal não pode mergulhar contemplativamente no que tem diante de si, pois tem de elaborar ao mesmo tempo o que tem atrás de si. Não apenas a multitarefa, mas também atividades como jogos de computador geram uma atenção ampla, mas rasa, que se assemelha à atenção de um animal selvagem. As mais recentes evoluções sociais e a mudança de estrutura da atenção aproximam cada vez mais a sociedade humana da vida selvagem (HAN, 2015, p. 31-32).

Mais adiante retornaremos ao debate sobre a incapacidade dos animais de aprofundamento contemplativo (ou de entediar-se). No momento, precisamos resolver alguns paradoxos criados por nosso atual regime de atenção. Ainda que Han demonstre claramente o retrocesso em torno da atenção multitarefa, não podemos desconsiderar o mérito que o mundo do trabalho atribui aos indivíduos portadores dessa capacidade. No caso dos jogadores de videogame, se considerarmos a ludi- 
ficação do trabalho (HAN, 2014b), então eles também são portadores desse mérito. Entretanto, se sairmos do mundo do trabalho e entrarmos no mundo da escola, o que antes era um mérito transforma-se em doença, ou seja, a atenção multitarefa transforma-se em déficit de atenção. Mesmo sem a disponibilidade dos conceitos atuais, Marshall McLuhan já percebia esse problema nas décadas de 1960 e 1970 quando dizia que "há um mundo de diferença entre o moderno ambiente do lar de informação elétrica integrada e a sala de aula" (MCLUHAN; FIORE, 1969, p. 46), ressaltando o encontro violento entre meios quentes (a sala de aula) e meios frios (a televisão). Por sua vez, no início do século XXI, Crary aborda o mesmo problema com os seguintes termos:

É evidente que muitas das medidas sistemáticas empregadas hoje para o controle eficiente da atenção funcionam, na melhor das hipóteses, de modo imperfeito. Muitas das formas de fixação, sedentarização ou atenção forçada implícitas na difusão dos computadores pessoais podem ter alcançado alguns desses objetivos disciplinadores, na produção daquilo que Foucault chamou de corpos dóceis. A proliferação de produtos eletrônicos e de comunicação garante que a docilidade esteja sempre ligada a padrões de consumo, mas as formas de desintegração social que acompanharam esse novo regime geraram comportamentos (por exemplo, crianças que não conseguem aprender) que se tornaram intoleráveis para esse sistema (CRARY, 2014a, p. 60-61).

Para além das contradições indicadas acima, é interessante perceber como a psicologia e a psiquiatria não mais conseguem afirmar a sociedade por meio da negatividade da doença. Michel Foucault dizia que "uma sociedade se exprime positivamente nas doenças mentais que manifestam seus membros" (FOUCAULT, 1988, p. 74), ou seja, quando reconhecemos certos comportamentos como doentios, estamos inversamente determinando os comportamentos aceitáveis de nossa sociedade. Entretanto, o que acontece quando um comportamento, até então classificado como doentio, torna-se uma meta social? Podemos exemplificar essa transformação a partir do acesso maníaco, como mostra Darian Leader:

As próprias características que a psiquiatria clássica atribuía ao acesso maníaco emergem como as metas do desenvolvimento pessoal. Livros e terapias de autoajuda promovem as ideias de autoestima e de uma autoconfiança e bem-estar acentuados. Nada é impossível, dizem-nos, devemos seguir nossos sonhos. E, se antigamente o sintoma principal da mania era definido como a busca compulsiva do estabelecimento de 
uma ligação com outros seres humanos, hoje em dia isso é quase uma obrigação: se você não está no Facebook ou no Twitter, você deve ter algum problema. O que antes eram sinais clínicos de psicose maníacodepressiva transformou-se na meta das terapias e do treinamento de estilo de vida (LEADER, 2015, p. 9).

Esta não é a mesma situação do déficit de atenção quando consideramos o mundo do trabalho? Não estamos diante de um sinal clínico agora avaliado como meta profissional? Podemos dizer, seguindo o pensamento de Han (2015), que os discursos da psicologia e da psiquiatria, antes bastiões da sociedade disciplinar, agora servem à sociedade do desempenho.

Abandonemos agora a próxima fase para retroceder muitas e muitas fases e lembrar de quando éramos chamados de animais em $O$ aberto, Giorgio Agamben aborda o antigo debate sobre o que separa homem e animal, apresentando desde a condenação religiosa da animalidade do homem (o pecado original) até a presunção do animal-homem que se autodenomina racional e pensante (homo sapiens). Indo direto ao ponto, nos interessa a discussão de Agamben (2017) sobre as ideias de Jakob von Uexküll e como estas ideias influenciaram o pensamento de Martin Heidegger sobre o debate em questão. No mesmo espírito que anima a fenomenologia e a física quântica, Uexküll entende que, como cada organismo percebe o mundo de forma diferente, não podemos falar em "o mundo objetivo", mas em vários meios ambientes, um para cada forma de perceber, ou seja, um para cada organismo. Para Uexküll, os elementos portadores de significado variam de organismo para organismo, transformando completamente a forma de perceber de cada um. O que é indiferente para o homem pode ser bastante significativo para o carrapato. Podemos explicar o meio ambiente humano nos mesmos termos da ecologia de Uexküll, ainda que ele seja carregado de muitos elementos portadores de significado caso comparado ao meio ambiente do carrapato. Contudo, para Heidegger, o homem é "um animal que aprendeu a entediar-se" (AGAMBEN, 2017, p. 111). Ao contrário do animal, que vive preso aos elementos portadores de significado do seu meio ambiente, o homem consegue se libertar deles quando alcança o tédio profundo:

Ao passo que, habitualmente, estamos constantemente ocupados com e nas coisas - ou melhor, especifica Heidegger, com os termos que antecipam aqueles que definem a relação do animal com o seu ambiente: "somos absorvidos pelas coisas, francamente perdidos nelas, frequentemente até atordoados por elas" -, no tédio nos encontramos, de súbito, 
abandonados no vazio (AGAMBEN, 2017, p. 103).

Paradoxalmente, o homem se define como homem porque é capaz de se libertar do meio ambiente humano. Na verdade, as conclusões de Agamben diferem ligeiramente das de Heidegger (veremos mais adiante), mas por ora precisamos compreender a profundidade desse paradoxo. Em Sociedade excitada, Türcke (2010) nos lembra do "desocupado" ilustrado por G. Anders, um homem que aparentemente parece não fazer nada, mas está completamente absorvido pelos elementos portadores de significado do seu meio ambiente: ele está bronzeando suas costas, ouvindo uma partida esportiva, mascando chiclete, lendo revista etc. Trata-se de um homem atordoado por sensações, que presta atenção em tudo, portanto, incapaz de se entediar. Portanto, a atenção é inimiga do tédio, pois ela serve para realçar os elementos portadores de significado do meio ambiente. Desse modo, a atenção impede a abertura do homem. Ainda que, por motivos mais amplos, Agamben (2017) conclui que, na pós-história (também chamada de pós-modernidade), essa abertura se fechou completamente: o homem agora vive tão somente para administrar sua vida biológica (saúde, conforto, autoestima, etc.), ou seja, para organizar os elementos portadores de significado do seu meio ambiente. $\mathrm{Na}$ visão do filósofo, isto é a realização máxima do biopoder. Podemos dizer que a atenção ocupa um papel importante na gestão desse poder, principalmente quando considerada como técnica. As tecnologias de atenção prendem o homem ao seu meio ambiente, o impedem de contemplar o vazio.

Podemos agora propor a seguinte hipótese: o tédio é uma dimensão humana ameaçada pelo atual regime de atenção. Esta hipótese acompanha outras lançadas pela teoria crítica. Por exemplo, Adorno (1983) propõe a hipótese da regressão da audição devido à subordinação da música em nossa sociedade: a "música de fundo" no bar, a música durante a caminhada, a música no rádio do carro, a "música de espera" do telemarketing etc. Aqui o problema parece inverso, pois em nenhum dos casos você está realmente prestando atenção na música: ela é apenas um acompanhamento. Entretanto, não podemos confundir o estado de atenção/distração próprio da modernidade com o tipo especial de atenção exigido por qualquer experiência estética: a atenção contemplativa. $\mathrm{O}$ que realmente estamos perdendo, para Adorno, é esse tipo especial de atenção. O tédio segue o mesmo caminho, pois ele próprio também é contemplação: a contemplação do vazio. É interessante lembrar, como 
faz Agamben (2017), do exemplo de tédio fornecido por Heidegger: um homem que perde o trem e agora deve esperar quatro horas pelo próximo. Inicialmente, ele tenta realizar diversos "passatempos" apenas para perceber que poucos minutos se passaram. Finalmente ele se deixa levar pelo tédio e perde completamente a noção do tempo. Mas o que aconteceria nos dias de hoje? Ele puxaria seu smartphone, colocaria uma música, se distrairia com os posts recentes ou com algum joguinho, enfim, sentiria o cansaço de esperar quatro longas horas. Ou seja, ele buscaria desesperadamente por elementos portadores de significado para preencher seu tempo, pois o tédio, para ele, é uma opção impossível ou mesmo indesejada. Ao quantificar até o último milímetro do tempo, como se ele fosse uma régua estendida ao infinito (a noção clássica de tempo), o que nos restou fazer é apenas preenchê-lo. Os "passatempos" tecnológicos estão aí para facilitar essa tarefa.

Retomando as conclusões de Agamben (2017), podemos agora voltar a falar do carrapato. Depois de aplicar suas descobertas à descrição do meio ambiente do carrapato, inclusive salientando a morte e reprodução do carrapato após seu primeiro e único banquete de sangue, Uexküll nos informa sobre um dado curioso, assim apresentado por Agamben:

\begin{abstract}
Somente nesse ponto, todavia, Uexküll nos informa que, no laboratório de Rostock, um carrapato foi mantido vivo por 18 anos sem alimentação, isto é, em condições de absoluto isolamento do seu ambiente. Desse fato singular ele não nos fornece nenhuma explicação, limitando-se a supor que durante esse "período de espera" o carrapato se encontrava em "uma espécie de sono semelhante àquele que nós experimentamos toda noite". Salvo por nos apresentar a consequência de que "sem um sujeito vivente o tempo não pode existir". Mas o que ocorre com o carrapato e com o seu mundo nesse estado de suspensão que dura 18 anos? Como é possível que um ser vivente, que consiste inteiramente na sua relação com o ambiente, possa sobreviver em absoluta privação dele? E que sentido faz falar de "espera" sem tempo e sem mundo? (AGAMBEN, 2017, p. 76-77).
\end{abstract}

Parafraseando o célebre romance de Philip K. Dick, os carrapatos sonham com o sangue das ovelhas? Podemos mesmo dizer, como faz Heidegger, que o homem é o único animal capaz de se entediar? Agamben sabe que é impossível responder a essa pergunta, o que o faz apostar no mistério como limite da filosofia e da ciência para compreender a vida: "Talvez o carrapato no laboratório de Rostock guarde com ele um 
mistério do 'simplesmente vivo' com o qual nem Uexküll nem Heidegger estavam preparados para se medir" (AGAMBEN, 2017, p. 112). O mistério do "simplesmente vivo" nos ensina a evitar essa falsa separação entre homem e animal e, assim, não concluir a favor de nenhuma possibilidade: nada de "os seres humanos são animais" ou de "os animais pensam e sentem como seres humanos". Para Agamben, sempre que a "máquina antropológica" tentou definir o ser humano, ela se baseou nessa falsa separação, ampliando ainda mais um abismo inexistente. Ao apelar para o mistério, o que ele nos pede é para apenas considerar a vida em suas muitas formas de existir, sem recorrer a classificações. Na verdade, mais que mistério, Agamben fala em ignorância, mas retomando o significado original da palavra: perdão. Quando seremos perdoados por desvelar o mistério da vida? Quando poderemos retornar à vida, banhados em ignorância? Quando poderemos simplesmente viver?

\section{REFERÊNCIAS}

ADORNO, Theodor W. O fetichismo na música e a regressão da audição. In: BENJAMIN, Walter; et al. Textos escolhidos. São Paulo: Abril Cultural, 1983.

AGAMBEN, Giorgio. O aberto: o homem e o animal. Rio de Janeiro: Civilização Brasileira, 2017.

BENJAMIN, Walter. A obra de arte na época de suas técnicas de reprodução. In: BENJAMIN, Walter; et al. Textos escolhidos. São Paulo: Abril Cultural, 1983.

CRARY, Jonathan. Suspensões da percepção: atenção, espetáculo e cultura moderna. São Paulo: Cosac Naify, 2014a.

24/7: capitalismo tardio e os fins do sono. São Paulo: Cosac Naify, 2014b.

FOUCAULT, Michel. Doença mental e psicologia. Rio de Janeiro: Tempo Brasileiro, 1988.

FRENCH, George. The art and science of advertising. Boston: Sherman, French \& Company, 1909.

HAN, Byung-Chul. Sociedade do cansaço. Petrópolis: Vozes, 2015.

. En el enjambre. Barcelona: Herder, 2014a.

. Psicopolítica. Barcelona: Herder, 2014b. 
HARRIS, Black. A guerra dos consoles: Sega, Nintendo e a batalha que definiu uma geração. Rio de Janeiro: Intrínseca, 2015.

HOPKINS, Claude. A ciência da propaganda. São Paulo: Cultrix, 1970.

JAMESON, Fredric. Pós-modernismo: a lógica cultural do capitalismo tardio. São Paulo: Ática, 2006.

KERCKHOVE, Derrick de. A pele da cultura. Lisboa: Relógio D’Água, 1997.

LARNED, William. Illustration in Advertising. New York: McGraw-Hill, 1925.

LEADER, Darian. Simplesmente bipolar. Rio de Janeiro: Zahar, 2015.

LEWIS, E. St. Elmo. Financial Advertising. Indianapolis: Levey Bros. \& Company, 1908.

LONDERO, Rodolfo Rorato. Por uma crítica fenomenológica da imagem técnica da publicidade: o problema da atenção. In: SEMINÁRIO DE PESQUISA EM CIÊNCIAS HUMANAS, 9., 2016, Londrina. Anais... São Paulo: Blucher, 2016. p. 143-150.

. Teorias da publicidade e cultura visual: a abordagem informacional de Abraham Moles em $O$ cartaz. In: ENCONTRO NACIONAL DE ESTUDOS DA IMAGEM, 4., 2013, Londrina. Anais... Londrina: Eneimagem, 2016. p. 2822-2832.

MCLUHAN, Marshall; FIORE, Quentin. O meio são as massa-gens. Rio de Janeiro: Record, 1969.

MOLES, Abraham. O cartaz. São Paulo: Perspectiva, 1974.

RIES, Al; TROUT, Jack. Posicionamento: a batalha pela sua mente. São Paulo: Thomson; Pioneira, 1987.

RIES, Al; RIES, Laura. A queda da propaganda: da mídia paga à mídia espontânea. Rio de Janeiro: Campus, 2002.

TÜRCKE, Christoph. Cultura do déficit de atenção (2015). Disponível em: <http:// www.revistaserrote.com.br/2015/06/cultura-do-deficit-de-atencao/>. Acesso em: 9 ago. 2017.

2010.

Sociedade excitada: filosofia da sensação. Campinas: Editora da Unicamp,

WILLIAMS, Raymond. Televisão: tecnologia e forma cultural. São Paulo: Boitempo, 2016. 